Dig Dis Sci. 2018 April ; 63(4): 851-855. doi:10.1007/s10620-017-4748-y.

\title{
Plastic Surgery: Cholangioscopic Intra-stent Balloon Retrieval of a Proximally Migrated Biliary Stent
}

\author{
Monique Barakat, MD, PhD, Mohit Girotra, MD, Abhishek Choudhary, MD, and Subhas \\ Banerjee, MD \\ Division of Gastroenterology and Hepatology, Stanford University, CA, USA
}

\author{
Keywords \\ ERCP; biliary stent migration; cholangioscopy
}

\section{Case presentation and evolution}

A 41-year-old man with a benign bile duct stricture was initially evaluated in our institution for endoscopic retrograde cholangiopancreatography (ERCP) with biliary stent exchange following plastic stent placement at an outside facility 2 months previously. His past medical history was notable for a motor vehicle accident resulting in abdominal crush injury and portal vein thrombosis. He then developed portal hypertension complicated by bleeding esophageal and gastric varices managed by splenectomy, with creation of a mesocaval shunt. Due to subsequent stenosis of the mesocaval shunt, he underwent portal vein thrombectomy and remains on warfarin therapy. He additionally developed portal bilopathy with a distal common bile duct stricture managed by stent placement.

Vital signs at the time of his procedure were notable for a heart rate of 82 beats/min, temperature of $37.2^{\circ} \mathrm{C}$, blood pressure of $101 / 72 \mathrm{~mm}$ of $\mathrm{Hg}$ and respiratory rate of $11 / \mathrm{min}$. Physical examination revealed healed incisions consistent with his surgical history and mild right upper quadrant abdominal tenderness. His laboratory studies, including liver function tests, were unremarkable.

At ERCP, the patient's ampulla was located in a poorly accessible portion in the distal second part of the duodenum. There was no evidence of a biliary stent protruding into the ampulla. Fluoroscopy located a stent in the right upper quadrant consistent with proximal migration of the stent into the bile duct (Figure 1). Several standard techniques typically utilized for retrieval of proximally migrated stents were sequentially employed preceded by extending the existing sphincterotomy. Multiple attempts to grasp the stent with rat-tooth forceps (mini and full-sized) under fluoroscopic guidance were unsuccessful. Efforts at capture with a polypectomy snare, a basket, and a stone extraction balloon also failed. Attempts to cannulate and retrieve the stent using Soehendra ${ }^{\mathrm{TM}}$ stent extractors were

Corresponding Author: Subhas Banerjee, MD, Associate Professor of Medicine, Division of Gastroenterology \& Hepatology, Stanford University School of Medicine, 300 Pasteur Drive, MC:5244, Stanford, CA 94305, Tel: 650-723-2623, Fax: 650-498-5174,

sbanerje@stanford.edu. 
similarly unsuccessful. Due to the length of the procedure a decision was made to terminate with a plan to attempt cholangioscopy-assisted stent retrieval at a follow-up ERCP. An $8.5 \mathrm{Fr}$ plastic stent was then placed alongside the proximally migrated stent.

At the time of repeat ERCP for stent exchange 11 weeks later, the most recently placed stent was removed and the proximally migrated stent was still evident on fluoroscopy. A Spyglass ${ }^{\mathrm{TM}}$ cholangioscope (Boston Scientific, Marlborough, Massachusetts, USA) was advanced into the bile duct; the migrated stent's distal end was embedded in the lateral wall of the distal bile duct with the proximal end impacted at the bile duct bifurcation, complicating attempts to directly cannulate the stent. The distal flange of the stent was grasped with a Spybite ${ }^{\mathrm{TM}}$ forceps, but due to the low closure force inherent with miniforceps, the device slid off with each attempt to dislodge the embedded stent (Figure 2A).

A 0.035 " guidewire was then advanced through the cholangioscope into the stent's flange side-hole and through the stent under visual and fluoroscopic guidance. A $4 \mathrm{~mm} \times 2 \mathrm{~cm}$ biliary stone extraction balloon was advanced into the stent through the side flange, inflated, and then used to push and dislodge the embedded distal tip of the stent. Once the stent was floating freely in the bile duct, the cholangioscope was used to direct the 0.035 " guidewire into the stent through its distal tip (Figure 2). The guidewire was advanced through the length of the stent. A $4 \mathrm{~mm} \times 4 \mathrm{~cm}$ biliary dilation balloon was then advanced over the guidewire into the mid-section of the stent (Figure 3A) and inflated to 6 atm within the stent to capture it, enabling successful stent retrieval over the guidewire (Figure 3B).

\section{Discussion}

Plastic biliary stents are utilized for the management of benign and malignant biliary strictures. Although proximal or distal biliary stent migration has been reported in 5-10\% of patients, clinically significant stent migration is rare. ${ }^{1}$ Adverse events associated with distal stent migration include recurrent biliary obstruction or cholangitis, intestinal perforation, cutaneous migration and even death. ${ }^{2,3}$ A proximally migrated stent may serve as a nidus for stone formation, and may be associated with biliary colic, cholangitis, and inflammation of the bile duct wall with consequent stricture formation. ${ }^{2}$ Risk factors for proximal and distal stent migration are not well-defined, but are thought to include placement for choledocholithiasis, use of very short or long stents, placement across a proximal bile duct stricture, and placement of multiple stents within a dilated bile duct. ${ }^{3}$ Approaches have been proposed to minimize the risk of proximal migration of the initially placed stent(s) due to friction, during placement of subsequent stents. In the 'anchor wire technique ${ }^{4}$ a stiff guidewire is directed through the distal tip of the initially placed stent, out of its distal flange side hole and towards the third part of the duodenum. The guidewire then prevents proximal migration of this stent during advancement of the next stent. An additional technique involves inflation of a dilation balloon within the bile duct alongside stents already in place in order to immobilize them. ${ }^{5}$

Proximally migrated stents may sometimes spontaneously descend and re-position themselves across the ampulla, an occurrence typically noted at subsequent procedures. When this does not occur, retrieval of these stents can be technically challenging. The 
simplest initial approach attempted by many endoscopists is to grasp and retrieve the stent using a rat-tooth forceps or a stone retrieval basket. In one series of 41 proximally migrated biliary stents, one third were successfully grasped and retrieved using these techniques. ${ }^{6}$ Direct stent capture with a polypectomy snare is also sometimes successful. When direct grasping techniques fail, endoscopists typically attempt guidewire-assisted stent capture and retrieval. These techniques require advancement of a long guidewire through the stent followed by retrieval using a Soehendra ${ }^{\mathrm{TM}}$ stent extraction device ${ }^{3}$ or a polypectomy snare directed by advancement over the guidewire. In the subset of patients where this fails, success has been reported following advancement of a biliary stone extraction balloon over a guidewire through the length of the stent, or through the stent's flange side-orifice, followed by balloon inflation to accomplish capture. ${ }^{7}$

Fluoroscopy-guided cannulation and advancement of a guidewire through a proximally migrated stent is usually possible using a tilting sphincterotome. Higher magnification fluoroscopy accompanied by collimation to minimize patient radiation exposure ${ }^{8}$ may be necessary in order to facilitate precise alignment of the sphincterotome with the stent. Successful stent cannulation may sometimes take a prolonged time as fluoroscopy typically permits only two-dimensional visualization. When this fails, cholangioscopy offers an additional visual dimension which enables easy and precise alignment with the stent and successful guidewire advancement. The stent may then be captured using a Soehendra ${ }^{\mathrm{TM}}$ stent extraction device, polypectomy snare, or stone extraction balloon. However, each of these guidewire-assisted stent capture approaches is cumbersome and not predictably successful. Moreover, the Soehendra ${ }^{\mathrm{TM}}$ stent extraction device requires a long guidewire.

We developed and have been using an alternative, easy and predictably successful intra-stent balloon extraction technique since 2000. A sphincterotome is used to insert a guidewire into the distal tip of the stent, then advanced across the length of the stent and beyond. A 4 $\mathrm{mm} \times 4 \mathrm{~cm}$ biliary dilation catheter (Hurricane balloon, Boston Scientific, Marlborough, Massachusetts, USA) is then advanced over the guidewire into the stent lumen, proximal to the stent's distal flange. The balloon is inflated to 5-6 atmospheres (atm) with resultant circumferential robust gripping and stent capture by the entire balloon length. The balloon and captured stent can then be easily withdrawn over the guidewire out of the bile duct and out through the working channel of the duodenoscope (Figure 4). Advantages of this technique include preservation of biliary access throughout the stent retrieval process and axial alignment of the extracted stent along the guide wire during stent extraction, thereby preventing bile duct laceration which might occur with the direct grasping techniques. Stent retrieval can be safely and effectively accomplished even if the stent has migrated proximal to a bile duct stricture.

It is important to have an adequate length of guidewire proximal to the stent, as the stent may migrate further proximally during balloon advancement due to friction associated with debris within the stent. We have found balloon inflation to 5-6 atm is ideal, as it prevents stent slippage and loss either within the bile duct or within the duodenoscope. If stent loss occurs within the duodenoscope working channel due to excessive friction or loss of inflation pressure, the balloon will be noted to exit the duodenoscope without the stent. In this event the balloon may be deflated, the duodenoscope elevator closed to prevent stent 
movement distally and the balloon is then re-advanced into the stent and again inflated to capture and remove the stent. If the balloon is inflated much above $6 \mathrm{~atm}$ within the stent, localized bulging of the stent may occur and resistance may be encountered when retracting the stent-balloon complex through the duodenoscope working channel. The balloon should be inflated proximal to the stent flange side orifice, to prevent bulging of the balloon through the orifice, with consequent friction. This technique is not ideal for 7 Fr stents since the balloon may not advance freely past the distal flange, especially if there is debris within the stent lumen. For smaller diameter migrated stents, the best retrieval approach may be a snare or Soehendra stent extraction device advanced over a guidewire to capture the stent.

This technique of stent retrieval over a guide wire is also useful for exchange of nonmigrated stents placed across technically challenging strictures (e.g. tight, complex hilar strictures) as it maintains guidewire access across the stricture, saving time that would otherwise be necessary for selective guidewire advancement. Similarly, stent exchanges that are challenging due to an inability to advance the duodenoscope near the ampulla as a result of tumor distortion of the duodenum or duodenal stenosis can be more safely accomplished using this technique.

\section{References}

1. Johanson JF, Schmalz MJ, Geenen JE. Incidence and risk factors for biliary and pancreatic stent migration. Gastrointest Endosc. 1992; 38:341-6. [PubMed: 1607087]

2. Cheruvu S, Kennedy R, Moshenyat Y, et al. Biliary stent migration: a brief review of potential complications and possible etiological factors. Am J Ther. 2014; 21:e124-9. [PubMed: 23508199]

3. Katsinelos P, Kountouras J, Paroutoglou G, et al. Migration of plastic biliary stents and endoscopic retrieval: an experience of three referral centers. Surg Laparosc Endosc Percutan Tech. 2009; 19:217-21. [PubMed: 19542849]

4. Hamada T, Nakai Y, Matsubara S, et al. Anchor-wire technique for multiple plastic biliary stents to prevent stent dislocation. World J Gastroenterol. 2011; 17:3366-8. [PubMed: 21876627]

5. Dumonceau JM, Heresbach D, Deviere J, et al. Biliary stents: models and methods for endoscopic stenting. Endoscopy. 2011; 43:617-26. [PubMed: 21614754]

6. Tarnasky PR, Cotton PB, Baillie J, et al. Proximal migration of biliary stents: attempted endoscopic retrieval in forty-one patients. Gastrointest Endosc. 1995; 42:513-20. [PubMed: 8674920]

7. Odemis B, Beyazit Y, Tanoglu A, et al. Endoscopic extraction of proximally migrated biliary stent by intrastent balloon inflation. BMJ Case Rep. 2014; 2014

8. Barakat MTTN, Huang RJ, Choudhary A, Kochar RJ, Kothari S, Banerjee S. Effects of a Brief Educational Program on Optimization of Fluoroscopy to Minimize Radiation Exposure During ERCP. Clinical Gastroenterology \& Hepatology. 2017 In press. 


\section{Key Points}

- Stent migration occurs in up to $10 \%$ of patients following placement of a plastic biliary stent

- Direct grasping techniques for stent retrieval are usually attempted by most endoscopists; however, guidewire-assisted stent capture and retrieval techniques may be safer.

- Intra-stent balloon extraction is a useful technique for safe, effective and predictable retrieval of proximally migrated biliary stents. It is also a useful technique for exchange of non-migrated stents where stent replacement may be challenging.

- Cholangioscopy-guided intra-stent balloon extraction is a useful ancillary technique for extraction of proximally migrated biliary stents, when guidewire advancement into the stent is challenging. 
A

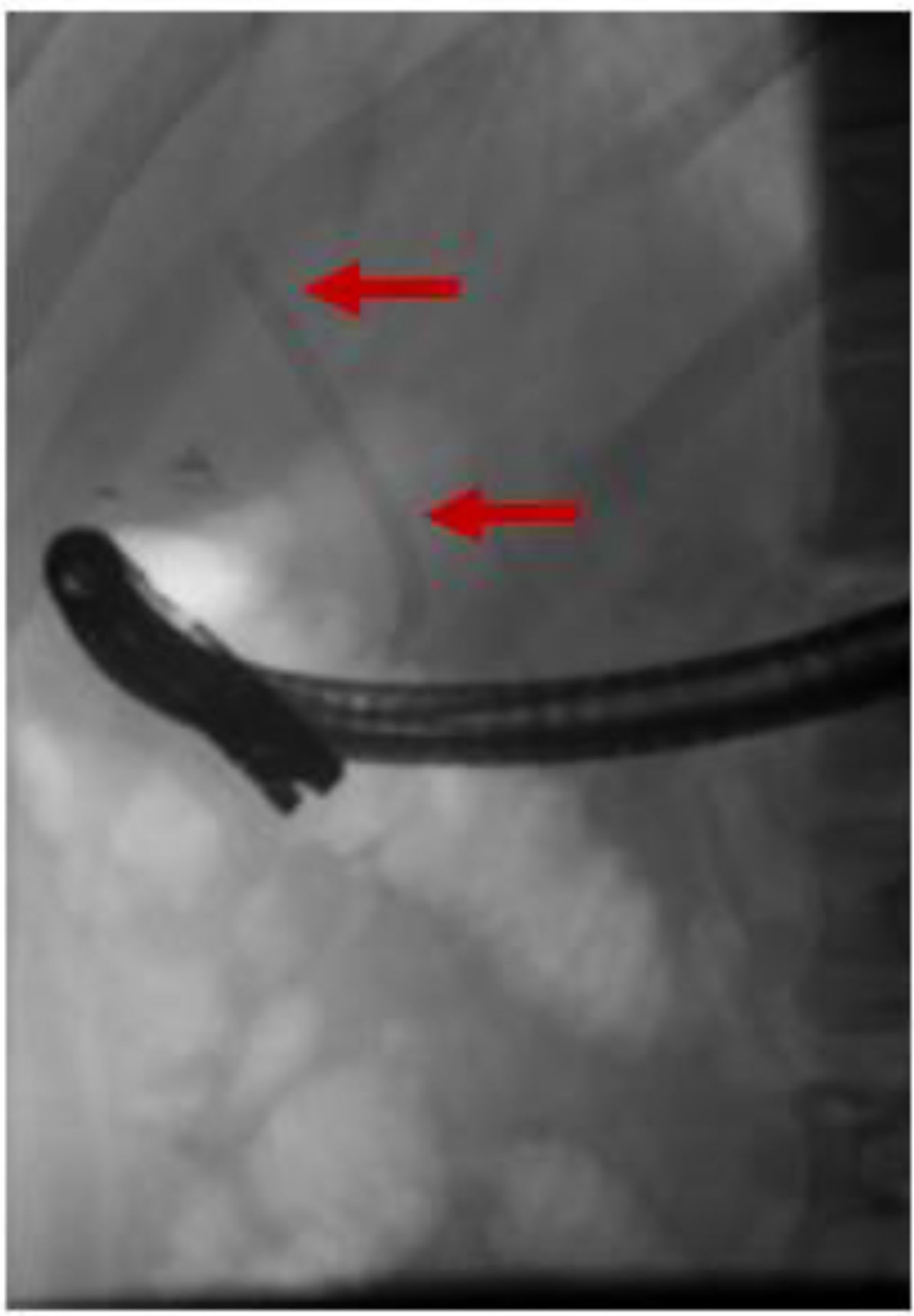

Figure 1.

Fluoroscopic image demonstrating the proximally migrated stent (indicated by arrows) in the right upper quadrant. 

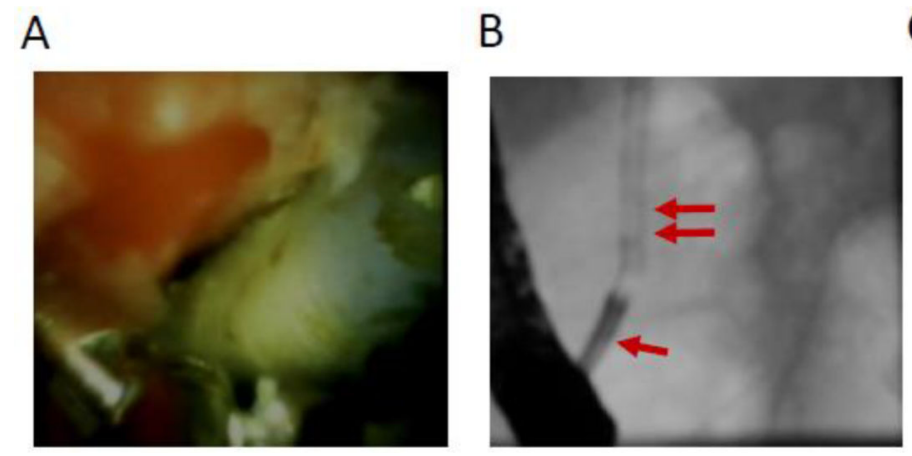

C

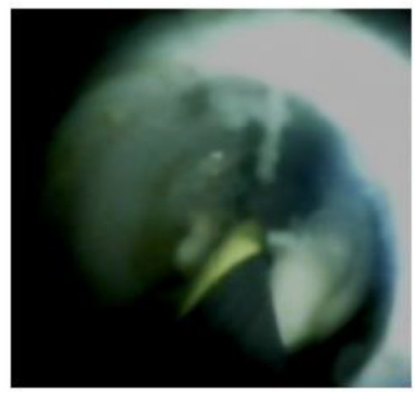

D

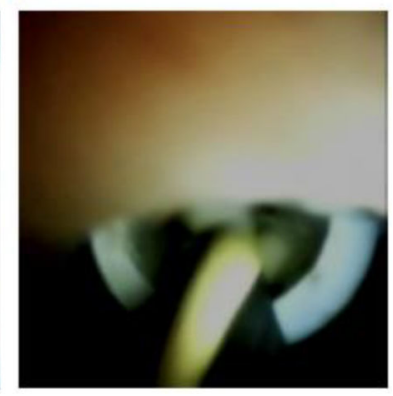

Figure 2.

(A) Cholangioscopic image depicting the distal end of the stent embedded in the bile duct wall with a Spybite ${ }^{\mathrm{TM}}$ forceps adjacent to stent in an attempt to grasp it. (B) Fluoroscopic and cholangioscopic images demonstrating Spyglass ${ }^{\mathrm{TM}}$ (single arrow) alignment with the stent (double arrows) with advancement of a guidewire into the stent under direct visualization. (C,D) Cholangioscopic view of guidewire advancement within the lumen of the proximally migrated stent. 
A

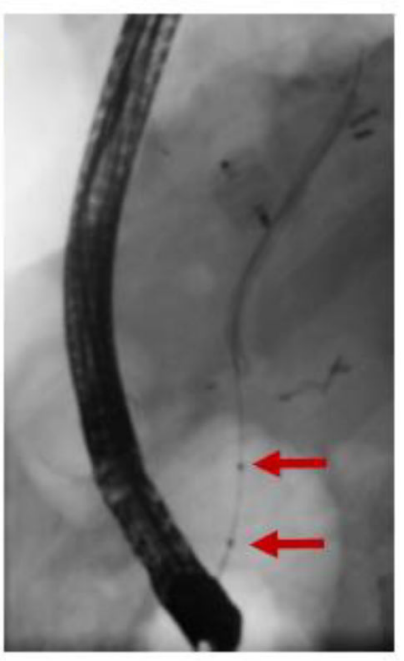

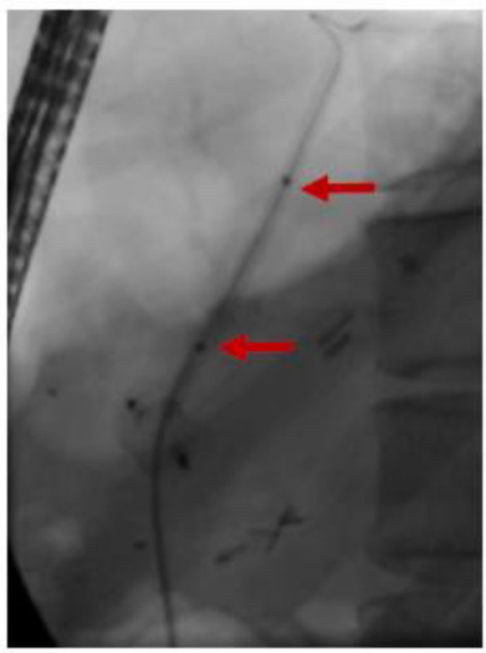

B

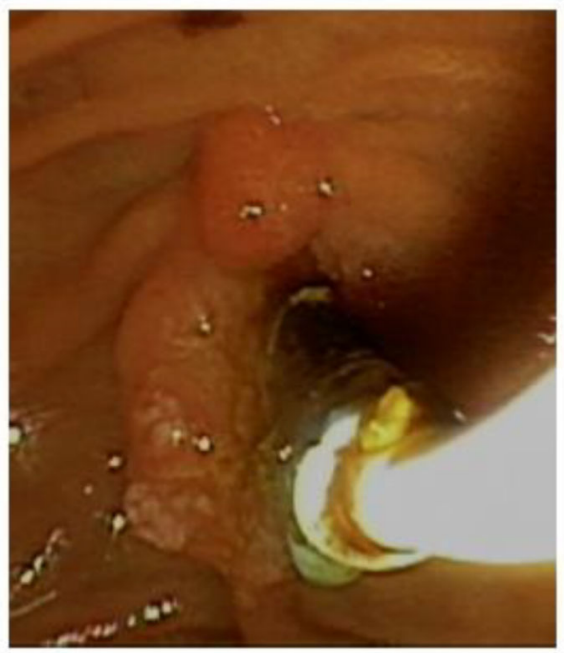

Figure 3.

(A) Fluoroscopic image demonstrating advancement of a dilation balloon within the stent lumen. Arrows indicate radiopaque balloon markings. (B) Endoscopic image showing removal of the migrated stent over a guidewire. The dilation balloon remains inflated within the stent. 

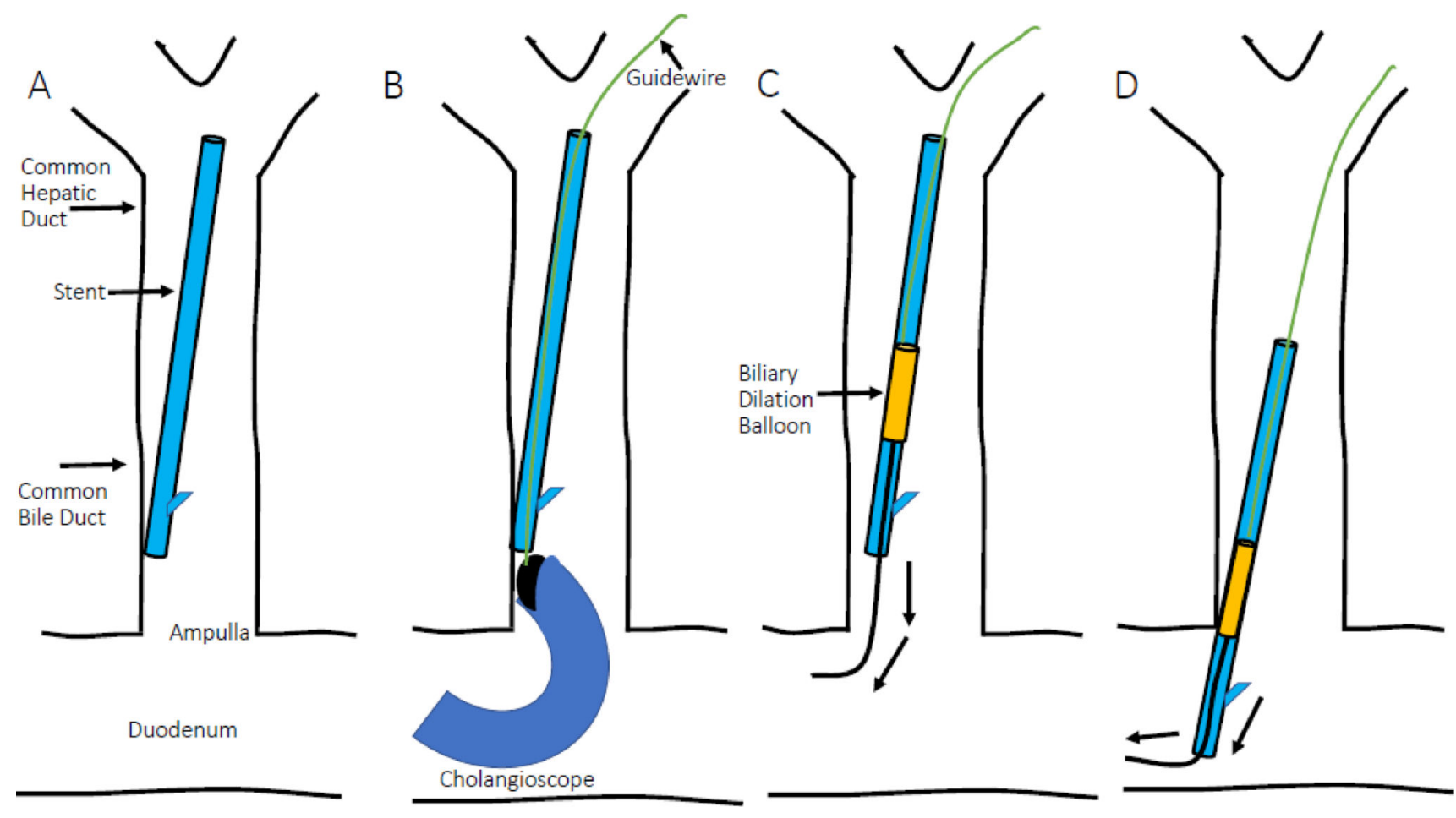

Figure 4.

Schematic representation of the proximally migrated stent (A), cholangioscopy-facilitated advancement of a guidewire into the proximally migrated stent's lumen (B) and a dilation balloon inflated within the proximally migrated stent lumen (C), followed by removal of the stent and balloon over the guidewire (D). 